\title{
Numerical Analysis of a New Block-Type Rail Bearing Beam for the Mid-Low-Speed Maglev Train
}

\author{
Wubin Wang $\mathbb{D},{ }^{1,2}$ Yandong Li $\mathbb{D},{ }^{2}$ Kang Xie $\mathbb{D}^{3},{ }^{3}$ Zhichao Huang, ${ }^{2}$ and Linchuan Shi ${ }^{2}$ \\ ${ }^{1}$ National Engineering Laboratory for Technology of Geological Disaster Prevention in Land Transportation, \\ Southwest Jiaotong University, Chengdu 611731, China \\ ${ }^{2}$ School of Civil Engineering, Southwest Jiaotong University, Chengdu, Sichuan 610031, China \\ ${ }^{3}$ Department of Civil Engineering, Central South University, Changsha 410075, China \\ Correspondence should be addressed to Kang Xie; xiekang1995@outlook.com
}

Received 12 November 2020; Revised 16 April 2021; Accepted 27 June 2021; Published 22 July 2021

Academic Editor: Claudio Mazzotti

Copyright (c) 2021 Wubin Wang et al. This is an open access article distributed under the Creative Commons Attribution License, which permits unrestricted use, distribution, and reproduction in any medium, provided the original work is properly cited.

\begin{abstract}
In this study, a new block-type rail bearing beam is presented, which consists of a cast-in-place base and prefabricated blocks. The finite element analysis is conducted to assess the proposed new rail bearing beam structure. The performed finite element method (FEM) simulation focused on the dynamic stress at the bottom of the rail bearing beam and structural internal force and deformation under the case of train loading, etc. Besides, the relationship between first-order natural frequency and activation frequency in the new support rail beam structure is analyzed and the beneficial effects on the internode connection structure are quantified. The results show that the increase in driving speed has the most significant effect on the vertical acceleration of the structure, and the self-vibration frequency of the structure is relatively large, which means the structure is safe. Since previous research seldom focuses on this block-type rail bearing beam, this study lays a valuable foundation for the construction of a rail bearing beam for the mid-low-speed maglev train.
\end{abstract}

\section{Background and Objectives}

1.1. Research Background. Magnetic levitation transportation, as a new type of rail transport system, uses two sets of magnets: one set to repel and push the train up off the track, and another set to move the elevated train ahead, taking advantage of the lack of friction [1]. It has advantages of high speed, safety, comfort, low noise, low pollution, strong climbing ability, and freedom of line selection [2]. Thus, the application of maglev technology in urban transportation, regional traffic, intercity traffic, and the national backbone network has a good prospect [3]. The original development goal of maglev transportation is high speed. However, as the maglev technology evolves, the lowspeed performance gradually attracts more and more attention [4]. Medium-low-speed maglev not only inherits the advantage of the safety of maglev technology but also has the benefits of the simple structure and low cost compared with high-speed maglev [5], which makes it more attractive to urban and suburban public transportation. Currently, there are two medium-low-speed maglev lines in operation in China: one is the Changsha Maglev line [6] and another is the Beijing S1 line [7], and Qingyuan Maglev special line is under construction [8].

As shown in Figure 1, the typical foreign medium-lowspeed maglev lines mainly include the Aichi High-Speed Transit Tobu Kyuryo Line in Japan [9], the Incheon Airport Maglev in South Korea [10], and the medium-low-speed test line (rail holding car) of The German Company Borg [11]. These research studies of medium-low-speed maglev lines mainly focus on an overpass. Low-lying sections also adopt the forms of the low-bearing platform and simply supported beam [12]. Seldom researches focus on low-lying structure in which rail bearing beam is directly placed on the subgrade.

Since the beginning of the 21st century, domestic researches on medium-low-speed maglev have been carried out, and several test lines have been built successively, mainly including the Changsha test line of the National 


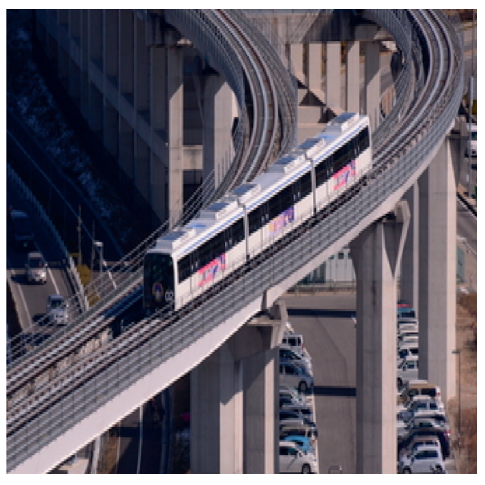

(a)

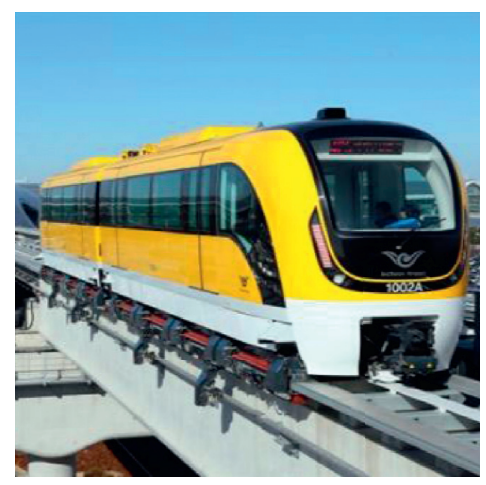

(b)

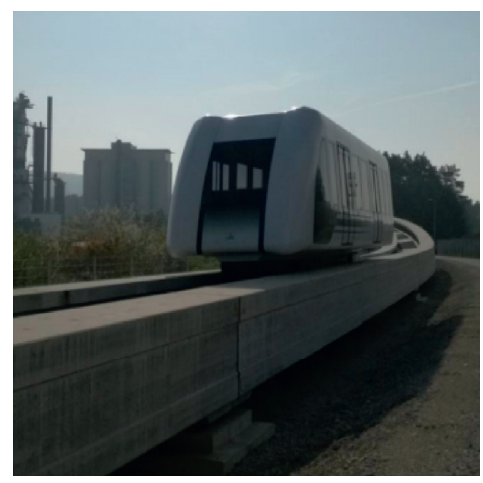

(c)

FIgUre 1: Typical medium-low-speed maglev lines: (a) Aichi High-Speed Line; (b) Incheon Airport Maglev; (c) medium-low-speed test line.

University of Defense Technology [6], Qingchengshan test line of Southwest Jiaotong University [13], Shanghai Lingang test line of Tongji University [14], Tangshan test line of CRRC [15], and Zhuzhou test line of CRRC [16], as illustrated in Figure 2.

On April 5, 2002, the first medium-low-speed maglev test line in China, developed and built by the National University of Defense Technology and other institutions, was opened to traffic in Changsha [6]. The test line is 204 meters in length, including a 100-meter radius curve and a gradient of $4 \%$, with a gauge width of 2 meters. The coach is 15 meters long and can carry more than 130 passengers. It is designed to travel at a speed of $150 \mathrm{~km} / \mathrm{h}$. In 2003, Southwest Jiaotong University established the medium-low-speed maglev test line in Qingcheng Mountain, Chengdu, Sichuan [13]. The maglev test track is $420 \mathrm{~m}$ long, and the coach is $11.2 \mathrm{~m}$ in length, $2.6 \mathrm{~m}$ in width, $3.3 \mathrm{~m}$ in height, and $18 \mathrm{t}$ in weight. By the end of 2006, the Shanghai medium-low-speed maglev test line was completed, with a total length of about $1.5 \mathrm{~km}$, and vehicle assembly and commissioning were also completed [14]. In November 2008, Shanghai low-speed maglev line realized an $85 \mathrm{~km} / \mathrm{h}$ trial operation of three connected trains, and in December of 2008, Shanghai lowspeed maglev line realized a $101 \mathrm{~km} / \mathrm{h}$ trial operation speed of trains. In June 2010, the Tangshan medium-low-speed maglev test line with a total length of 1547 meters was completed [15]. It can comprehensively detect the advantages of trains in the cases of straight lines, curves, and large slopes of urban tracks. In addition, the short test line of only about 1,000 meters covers various structures such as $70 \%$ gradient, 100 or 50 meters radius space rotation and turning. Besides, the coach is $15 \mathrm{~m}$ in length and $3 \mathrm{~m}$ in width.

However, the Changsha test line, the Qingchengshan test line, the Shanghai Lingang test line, and the Tangshan test line did not adopt the low-lying structure in which the rail bearing beam is directly placed on the subgrade. The medium-low-speed maglev low-lying structure is a structure composed of the subgrade and the rail bearing beam arranged on the subgrade, which is mainly used for lowfilling and shallow-excavation sections. Among these, rail bearing beam is necessary for the low-lying structure, which is composed of the lower base plate (base) and the upper beam body. Then, the lower base plate (base) is buried in the subgrade, and the upper beam body is used to install the power-supplying track and supported track structure. According to [17], the rail bearing beam of the low-lying structure should adopt the "convex" type. Moreover, it is required to satisfy the following demands: (1) simple and beautiful, (2) conducive to vibration reduction, (3) noise reduction, (4) convenient for construction, maintenance, and operation, and (5) safe and comfortable.

1.2. Research Objectives. Various types of rail bearing beams, including solid beams, box beams, and frame column beams, have been used in the medium-low-speed maglev lines [18]. Although current supported beam structure technology can meet the design requirements, some problems still exist in the economy and technology. For example, the solid beam may waste more masonry, the box beams lining can not be dismantled, and the smaller components of frame column beams are inconvenient for construction. Additionally, rail bearing beams of low-lying structures adopt the construction in the form of cast-in-place, which means that the construction period is much longer. Jahangiri and Zakeri studied the dynamic responses of the train-bridge system under a one-way and two-way high-speed train passing by the 3D finite element modeling [19]. Zakeri et al. studied the vibrations of a curved beam considering vertical and horizontal load [20]. Xia et al. used a three-dimensional finite element model to represent a long suspension bridge to investigate a dynamic train-long suspension bridge interaction [21]. However, these research studies did not mention the block-type rail bearing beam.

In this paper, on the basis of the existing researches on the problems and improvement demand, we present a new solution of rail bearing beam, using large-scale nonlinear finite element analysis software to do finite element analysis on the new rail bearing beam structure. In this process, we analyze the dynamic stress at the bottom of the rail bearing beam and structural internal force and deformation under the case of train loading, etc. Besides, the relationship between first-order natural frequency and activation frequency in the new support rail beam structure was explored, and a 


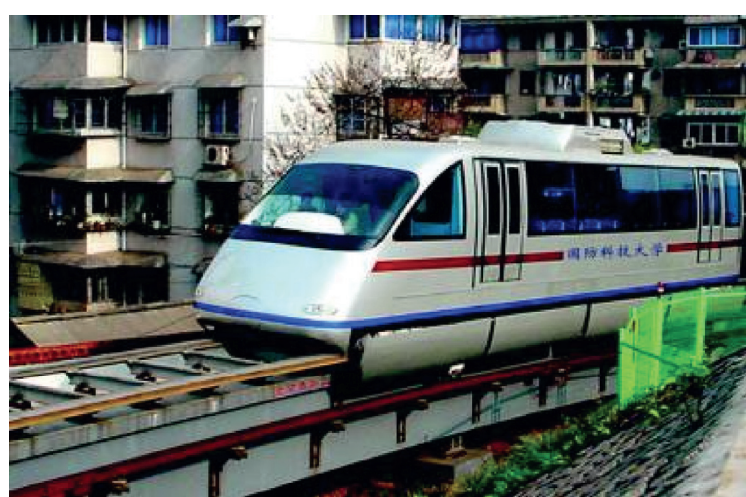

(a)

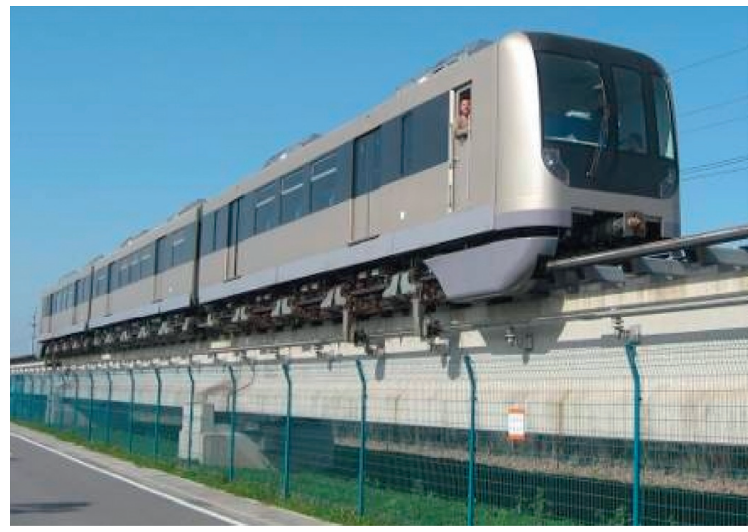

(c)

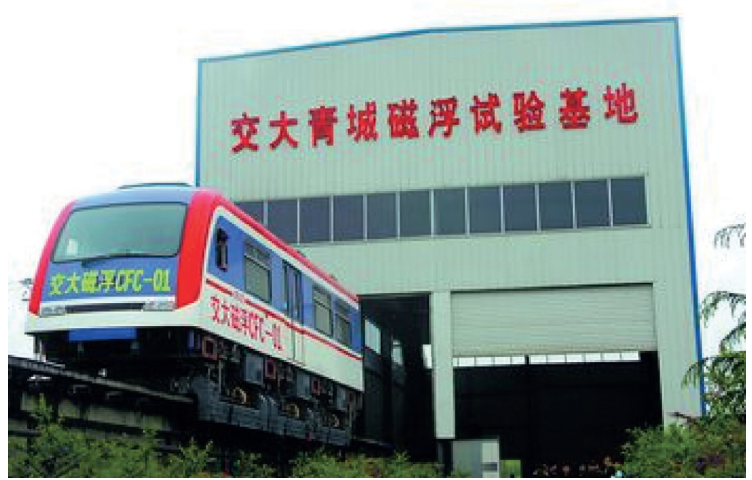

(b)

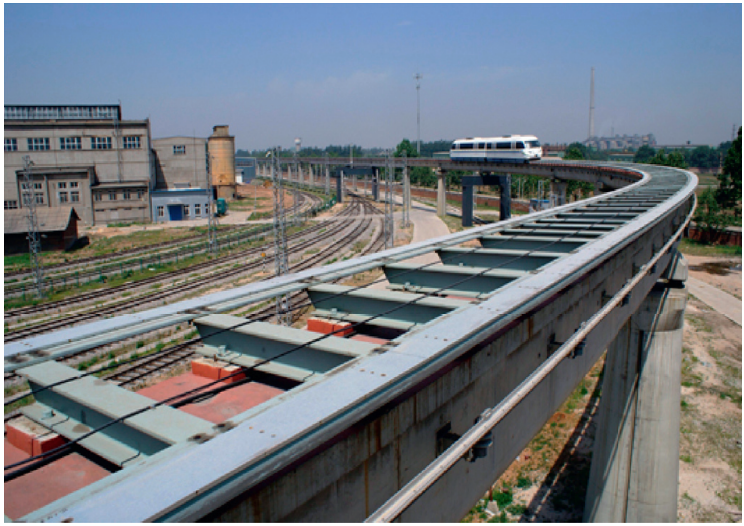

(d)

Figure 2: Domestic medium-low-speed maglev lines: (a) Changsha test line; (b) Qingchengshan test line; (c) Shanghai Lingang test line; (d) Tangshan test line.

quantitative analysis of the beneficial effects on the internode connection structure was implemented.

\section{Introduction of the Rail Bearing Beam}

2.1. Existing Rail Bearing Beam. In July 2012, the mediumlow-speed maglev test line of China Zhuzhou locomotive corporation was all completed and commissioned, with a total length of $1.7 \mathrm{~km} \mathrm{[16].} \mathrm{Within} \mathrm{about} 800$ meter length of the line, the rail bearing beam was placed directly on the subgrade with a low-lying structure, which is the first attempt in China. Since the medium-low-speed maglev train suspension clearance is only $8 \mathrm{~mm}$ or so, the requirements of deformation of the offline structure are more stringent. At that time, worldwide experts generally believe that maglev rail transit should not adopt the low-lying structure of subgrade. Thus, at the beginning of the design of Zhuzhou test lines, there is still a lack of researchabout the rail bearing beam of a low-lying structure. In the end, they adopted three types of rail bearing beam designing schemes, including box beam, frame column beam, and transverse door-frame beam, as shown in Figure 3.

China Railway ErYuan Engineering Group started researches on the low-lying structure of rail bearing beams based on the Zhuzhou test line [16]. By the simulation analysis and site test of train on the rail bearing beams, the results showed that all three types of rail bearing beam structure have good performances and can meet the design requirements. Among these three types, the overall performance of the box beam is the best while the response of the three-axis acceleration is the smallest. However, it is more conservative compared with the other two types of beams. The vertical displacement caused by the stress of each beam structure and the additional stress inside the lower bed filler has no obvious difference, and the absolute value is small. In addition, the floor height of the beam structure of the rail bearing beam can be appropriately reduced to decrease the dead weight.

Based on the relevant research results of the Zhuzhou test line [16], the Changsha Maglev line mainly uses two types of rail beams for the low-lying structure [22], as shown in Figure 4. The main line section and depot of Changsha Maglev line used 6 sections of low-lying structures, of which solid beams are used in the main line section of the section, and frame column beams are used in the depot section. This is the world's first medium-low-speed maglev operating line with a low-lying structure in which the rail beam is directly placed on the subgrade. Furthermore, it broke the technical bottleneck that worldwide experts generally believed that maglev rail transit should not use low-lying structure subgrades. On top of that, it has improved the applicability of medium-low-speed maglev transportation to geological and 


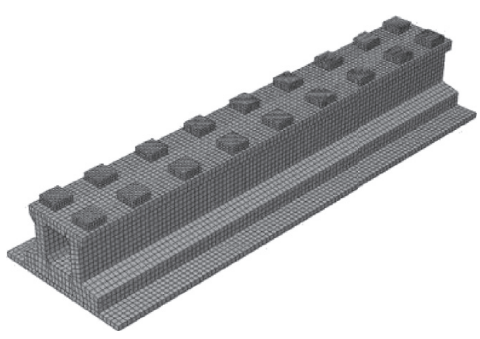

(a)

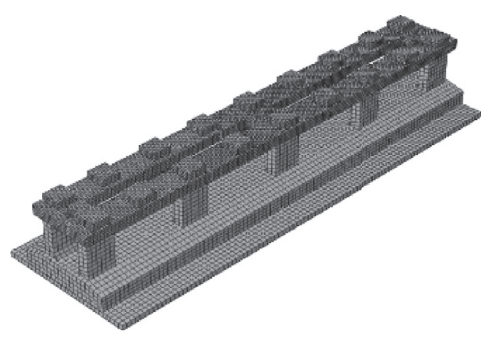

(b)

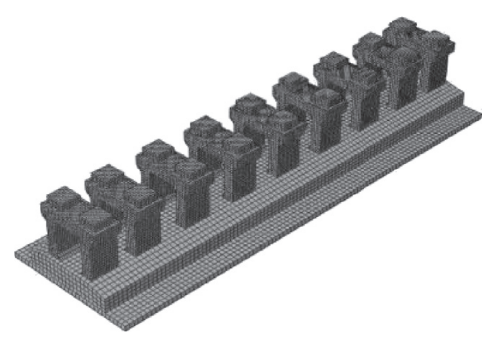

(c)

FIGURE 3: Schematic diagram of rail bearing beam of the low-lying structure of Zhuzhou test line: (a) box beam; (b) frame column beam; (c) transverse door-frame beam.

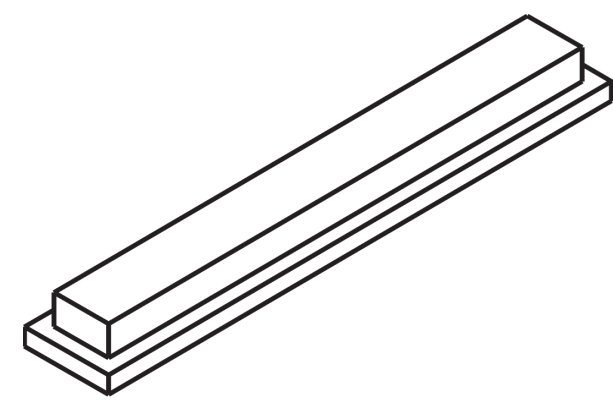

(a)

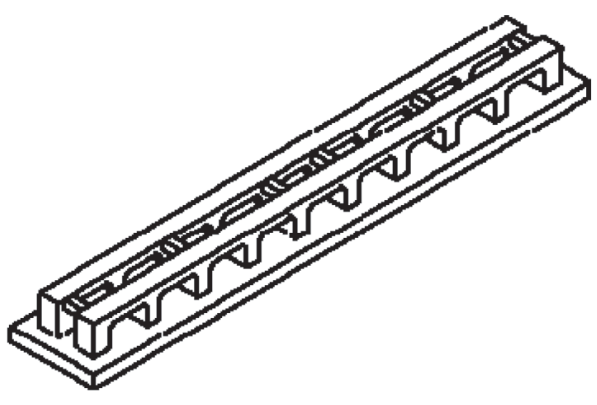

(b)

Figure 4: Schematic diagram of rail bearing beam of the low-lying structure of Changsha test line: (a) solid beams; (b) frame column beam.

topographical conditions and reduced the project cost. In addition, it maintained the leading edge in technology worldwide.

Based on the Changsha Maglev line, China Railway Siyuan has conducted a relatively systematic study on lowlying structural rail beams [23]. They conducted researches on the load system, force mode, deformation characteristics, control standards, and related structural measures of the rail beams. Based on the results, the solid rail beam can be designed according to the elastic foundation beam. For other structural forms, the rail beam can refer to the elastic foundation beam. Meanwhile, the corresponding model should be calculated according to the upper beam structure type. Note that there are elastic supports and friction constraints between the bottom plate of the rail beam and the subgrade under the beam. So, when necessary, the adverse effects of the subgrade void under the beam on the force and deformation of the rail beam should be considered.

However, the existing rail beam technology mainly has the following problems:

(1) The advantages of box beams are material saving, high rigidity, and small deformation. However, due to the small structural size of the rail beam, the construction of small box components is more difficult. Besides, the inner mold cannot be removed, which increases the construction cost and is inconvenient for maintenance. The water collected between the line sections cannot be discharged to the road shoulders on both sides

(2) The advantages of frame column beams are light structure and material saving. However, because columns and beams are all small components, each component needs to be poured with a formwork separately. Thus, the construction process is cumbersome, and the construction cost is relatively high

(3) The advantages of solid beams are simple structure and convenient construction. However, solid beams have heavy self-weight and require high foundation bearing capacity. Besides, solid beams could waste masonry materials, are greatly affected by temperature loads, and cannot discharge the water between the two-lane sections to the road shoulders on both sides

(4) A cast-in-place rail support structure needs to be set between the rail beam and the steel sleeper to realize the accurate adjustment of the rail row structure. In addition, the size of the rail support is small; thus, the construction is more difficult, and the construction cost is increased

For medium-low-speed maglev projects that have been built and are under construction, low-level structural rail beams are all cast-in-place, which is greatly affected by external factors such as environment and temperature. Thus, 
construction is more difficult in the winter and rainy seasons. At present, there are no application examples and related researches of prefabricated and assembled low-lying structural rail beams.

2.2. Proposed Block-Type Beam. In this study, a new blocktype rail bearing beam, which consists of a cast-in-place base and prefabricated blocks, was proposed in order to improve the existing rail bearing beam. The structure of the blocktype rail bearing beam is illustrated in Figure 5. The blocks are perpendicular to the line direction and are arranged at intervals along the line direction. The center line of the blocks is also the center line of the rail structure, and the bottom is embedded in the base. The top exposed is used to support the track structure and to install the power supply rail. The arrangement position and direction of each block is reasonably matched with the position of the sleeper and the connecting member of the track structure. The block and the base are connected by connecting steel bars reserved at the bottom of the block, and then, the block and the base are poured into an integral structure through the cast-in-place base.

During operation, the track structure and train load are transferred to the base through multiple blocks and then transferred from the base to the subgrade. The support rigidity of the base and the subgrade below the base is used to meet the smoothness requirements of the track structure. The friction forces of the seat, backfill layer, and the base are used to meet the requirements of vertical and horizontal stiffness, thus ensuring the safe operation of the maglev train.

\section{FEM Simulation of the Rail Bearing Beam}

A numerical calculation model was established through ABAQUS software [24] to study the force and deformation of the new block-type rail bearing beam structure under the action of maglev load. First, the rail bearing beam structure with the actual size was established. Then, in order to study the internode structure of the dowel steel, two models were established with and without the dowel steel between bases. The models simulated the actual uniform load effect of the maglev train and determined the influence of the dowel steel. In order to study the sensitivity of the rail beam structure to the load, temperature load, horizontal load, and vertical train load were considered separately. Thus, the degree to which different loads affect the structure can be determined. Finally, the most unfavorable load combination was considered, and the stress distribution, vertical deformation, and horizontal displacement of the column structure under this situation were studied. The three-dimensional model of the block-type rail beam is shown in Figure 6. The specific introduction is as follows.

First, the base of the rail beam was explained. The rail beam has three sections, named from left to right as shown in Figure 7. The length of the first section is $11.58 \mathrm{~m}$, having a length of the expansion joint of $0.02 \mathrm{~m}$. Therefore, the longitudinal center line of the line was taken as the $X$-axis,

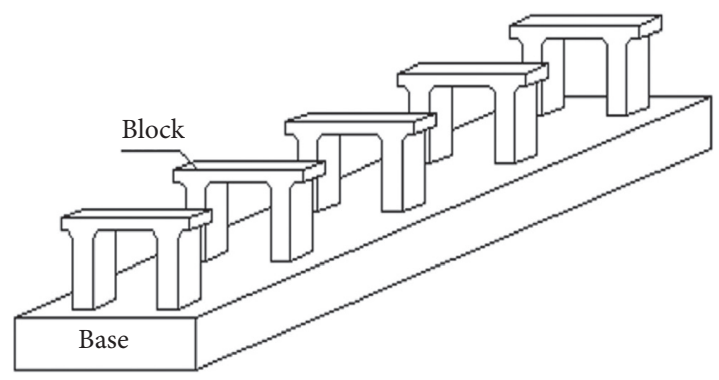

FIGURE 5: Schematic diagram of new block-type rail bearing beam.

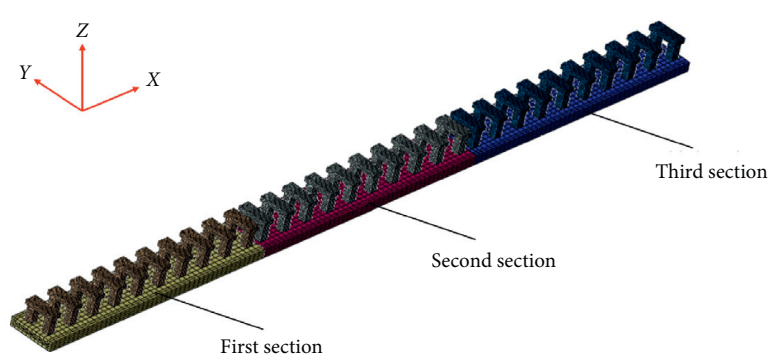

Figure 6: The 3D model of block-type rail beam.

and the cross-sectional direction of the second section of the rail beam was taken as the $Y$-axis to establish a coordinate system as shown in Figure 7. Thus, the coordinates of the left and right ends of the second section of the rail beam are $-5.8 \mathrm{~m}$ and $5.8 \mathrm{~m}$, respectively. In addition, the coordinates of the left end of the first section of the bearing beam and the right end of the third section are $-17.4 \mathrm{~m}$ and $17.4 \mathrm{~m}$, respectively. In total, the length of three sections of the base is $34.78 \mathrm{~m}$, and the coordinates of both ends of the base along the $Y$-axis are $\pm 1 \mathrm{~m}$.

3.1. Model Geometry. The structure of the rail bearing beam is mainly divided into three parts: the top plate, the column, and the base. In our model, three rail bearing beams were built with a length of each base under a rail bearing beam of $11.58 \mathrm{~m}$ and an expansion joint of $20 \mathrm{~mm}$ between sections. Each pair of bases is connected by dowel steel (Q235 steel, $\varphi 50 \times 5 \times 700 \mathrm{~mm}$ ), and the total length of the rail beam base is $34.78 \mathrm{~m}$. The spacing between the blocks is $1.2 \mathrm{~m}$, and the specific structural dimensions are shown in Figure 8.

As shown in Figure 9(a), the upper part of the rail beam is equipped with a track structure. Above the top plate is an $\mathrm{H}$-shaped rail, which is connected by backing plates and gaskets as shown in Figure 9(b). In our simulation, different parts were connected by binding instead of bolting. Additionally, F-shaped rails are laid along both ends of the $\mathrm{H}$-shaped rail, and the $\mathrm{F}$ rail is loaded to simulate the actual maglev train load.

As shown in Figure 10, the subgrade structure is composed of a $0.3 \mathrm{~m}$ subgrade surface layer, a $1.2 \mathrm{~m}$ subgrade bottom layer, and the underfill. There is a $0.1 \mathrm{~m}$ thick concrete cushion under the rail beam base, and a backfill soil layer is set around the base. The overall length of the model is $36.8 \mathrm{~m}$ and the width is $20.5 \mathrm{~m}$. 


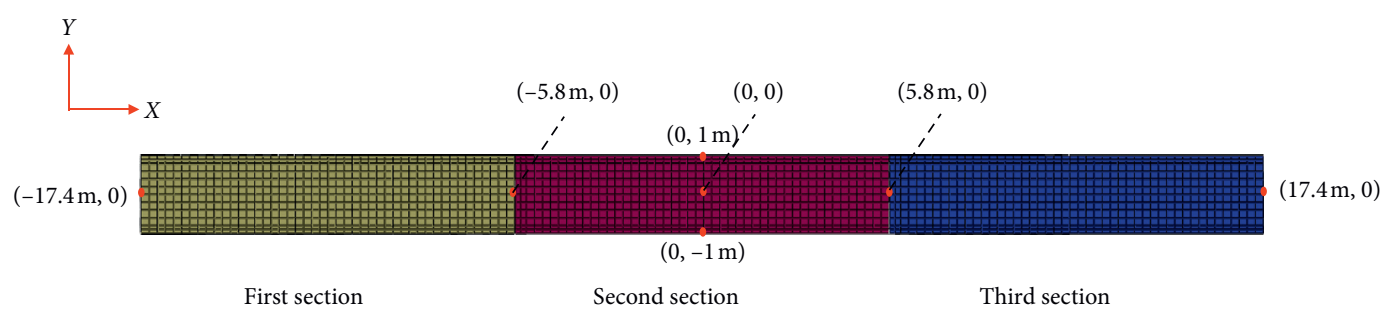

FIGURE 7: The naming diagram of the rail beam base.

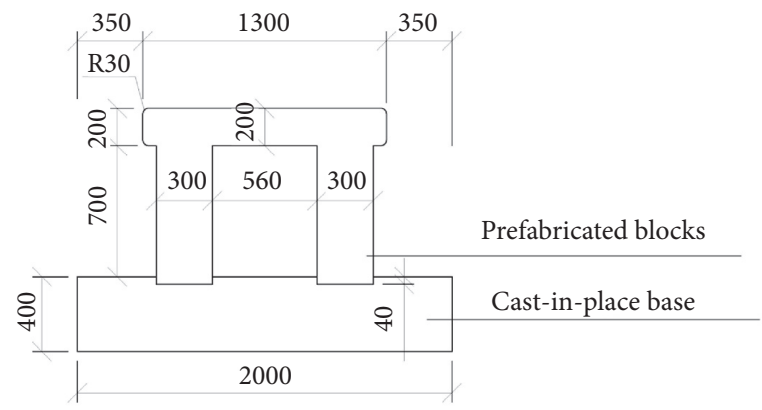

(a)

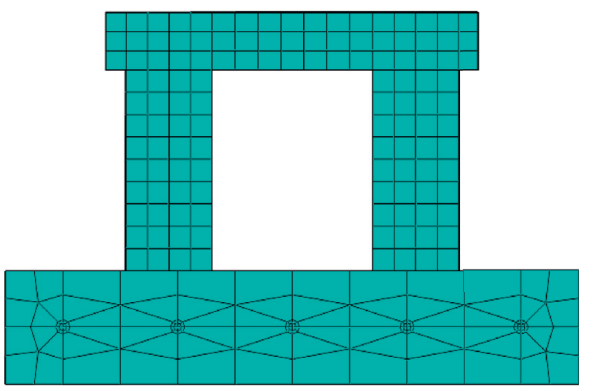

(b)

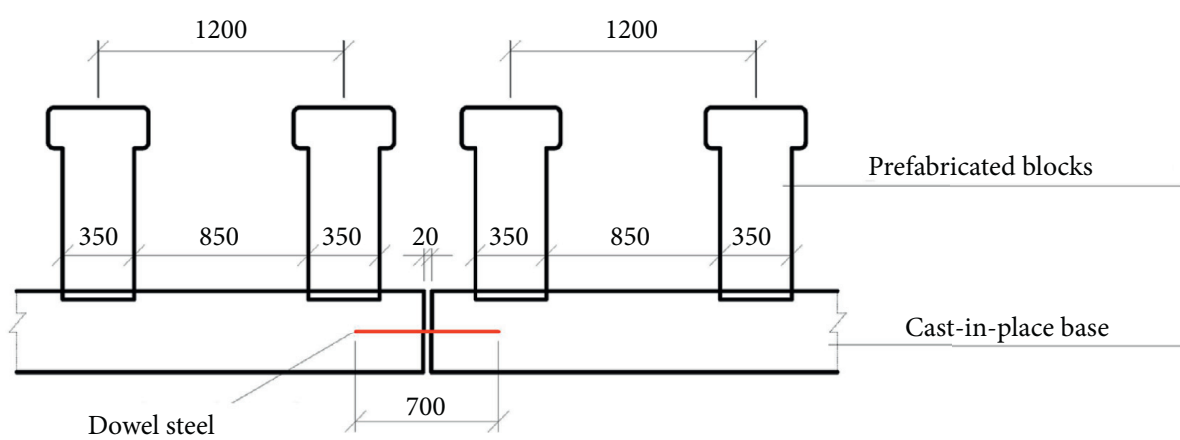

(c)

FIgURE 8: Specific structural dimensions: (a) cross-section size; (b) finite element mesh diagram; (c) local dimension of longitudinal section of rail beam structure.

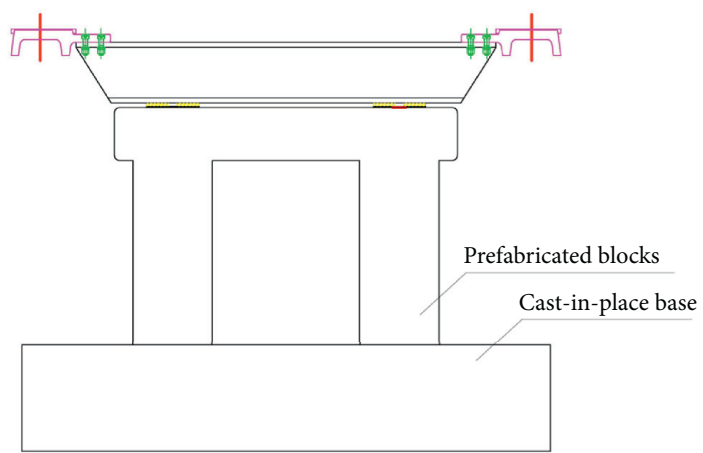

(a)

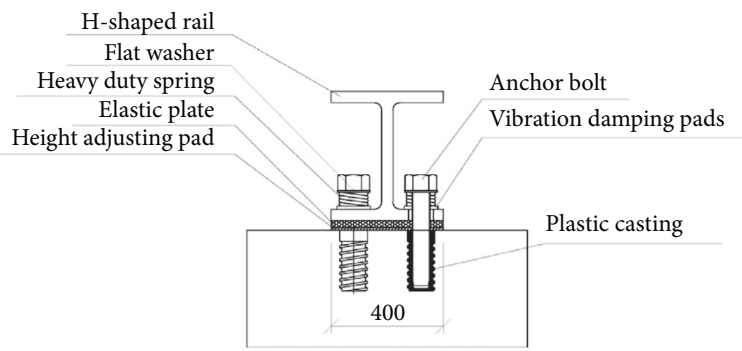

(b)

Figure 9: Schematic diagram of the rail: (a) cross-sectional view of rail row and rail beam structure; (b) schematic diagram of rail fastener connection. 


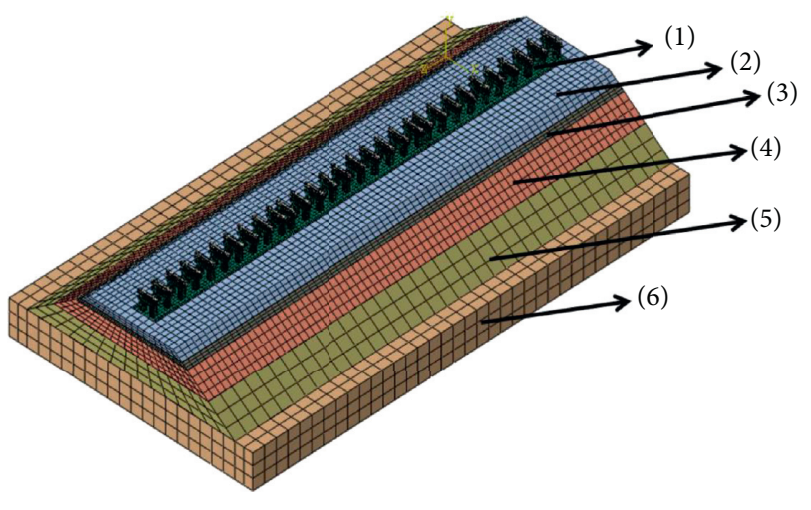

(1) Rail bearing beam

(2) $0.5 \mathrm{~m}$ backfill layer

(3) $0.3 \mathrm{~m}$ subgrade surface layer

(4) $1.2 \mathrm{~m}$ subgrade bottom layer

(5) $1.5 \mathrm{~m}$ embankment soil

(6) $2.5 \mathrm{~m}$ foundation soil

Figure 10: The 3D model structure diagram.

3.2. Input Parameters. The rail bearing beam structure is made by pouring C40 concrete, and the parameters of the concrete cushion under its base take the C25 concrete parameters. The model parameters used in all the structures simulated in this paper are shown in Table 1.

3.3. Input Loadings. The load acting on the top surface of the rail beam mainly includes the dead load and the vertical live load of the train. The dead load includes the self-weight of the rail beam structure and the self-weight of the track structure acting on the rail beam. The calculation shows that the dead load value is about $452.22 \mathrm{~kg} / \mathrm{m} 4.5 \mathrm{kN} / \mathrm{m}$. In our simulation, it is applied by the gravity method of the track structure. According to the "Basic Technical Parameters of Qingyuan Maglev Vehicle," a load of a single train in suspension is shown in Figure 11, and the uniform load is $12.9 \mathrm{kN} / \mathrm{m}$. Therefore, the actual simulated load situation in the calculation is shown in Figure 11. There are three trains in total, and the distance between each train is $1.68 \mathrm{~m}$. According to the actual load width of the F-shaped rail subjected to the maglev train, a load with a width of $0.218 \mathrm{~m}$ is established in the model. And it is converted into an area load of $59.174 \mathrm{kPa}$, which is taken as $60 \mathrm{kPa}$.

In addition to the vertical load, based on theoretical analysis, the influence of horizontal load and temperature load should be considered. Therefore, both loads are applied separately to analyze the degree of influence of these two loads on the structure of the rail beam. On this basis, the most unfavorable load combination was considered, and the stress and deformation of the structure were explored. The application of the load value is consistent with the theoretical analysis; see Table 2 for details.

3.4. Modeling Scenarios. In order to explore the structural force and deformation characteristics of the rail bearing beam structure under the action of maglev load, two working conditions were simulated according to the structural characteristics under different load conditions.

Working condition 1 aims to simulate trains passing at speeds of $100 \mathrm{~km} / \mathrm{h}, 140 \mathrm{~km} / \mathrm{h}$, and $160 \mathrm{~km} / \mathrm{h}$ under the boundary conditions of the dowel steel. Under the dynamic load of the train at different speeds, the dynamic acceleration analysis, displacement response analysis, and dynamic coefficient analysis of the rail bearing beam were implemented.

Working condition 2 is to analyze the internal force and deformation of the rail beam under the boundary conditions of the dowel steel, considering the most unfavorable working condition combinations such as dead load, live train load, and temperature load. The content includes deflection, turning angle, bending moment, and shear force of base, horizontal displacement, bending moment, and shear force of blocks.

3.5. Model Validation. Considering the accuracy of the numerical simulation software, the vertical deformation and acceleration response results of the $F$ rail under the driving speed of $100 \mathrm{~km} / \mathrm{h}$ in this study are extracted to verify the reliability of the model. The results are compared with the field measurement of the Zhuzhou medium and low-speed maglev test line $[25,26]$, as shown in Table 3 . The calculation results are shown in Figure 12.

Comparing the structure response value, deformation, and acceleration distribution law obtained by model calculation and field measurement, it can be seen that the value calculated by the model has a certain deviation from the field measurement, but it is within the acceptable range. In addition, the distribution law of structure response by simulation is basically consistent with the measurement. It shows that the finite element model in this study is reliable.

\section{Numerical Results and Discussion}

4.1. Analysis of Train Response at Different Speeds. In order to determine the response law of the rail beam structure under different driving speeds, the static load, $100 \mathrm{~km} / \mathrm{h}$, $120 \mathrm{~km} / \mathrm{h}$, and $160 \mathrm{~km} / \mathrm{h}$ working conditions were simulated, respectively, and the dynamic displacement and dynamic acceleration response of the structure under different working conditions were studied. Note that the vertical deformation is caused by the dynamic load of the train, without considering the gravity of the structure.

4.1.1. Dynamic Displacement Response Analysis. When the static load acts on the longitudinal middle position of the model, the vertical deformation distribution curve of the top plate along the longitudinal direction is shown in Figure 13. The deformation law of a single section of rail bearing beam shows a trend of large in the middle and small at the beam end. The maximum vertical deformation occurs at the position of the middle top plate of the second section of the rail beam $(X=0)$, with a value of $0.2776 \mathrm{~mm}$. Due to the smaller constraints at the expansion joints, the vertical deformation is reduced to a value of $0.183 \mathrm{~mm}$. 
TABle 1: Model parameter table.

\begin{tabular}{lccccc}
\hline Structure & Density $\left(\mathrm{kg} / \mathrm{m}^{3}\right)$ & Elasticity modulus $(\mathrm{MPa})$ & Poisson's ratio & Friction angle & Cohesion $(\mathrm{kPa})$ \\
\hline Rail bearing beam & 2500 & $3.25 \times 10^{4}$ & 0.15 & - & gai- \\
Concrete cushion & 2450 & $2.8 \times 10^{4}$ & 0.165 & - & - \\
Dowel steel & 7850 & $2.1 \times 10^{5}$ & 0.33 & 20 & 15 \\
Backfill layer & 1700 & 100 & 0.35 & 30 & 80 \\
Surface layer of base & 2100 & 140 & 0.25 & 25 \\
Bottom layer of base & 2000 & 120 & 0.3 & 20 \\
\hline
\end{tabular}

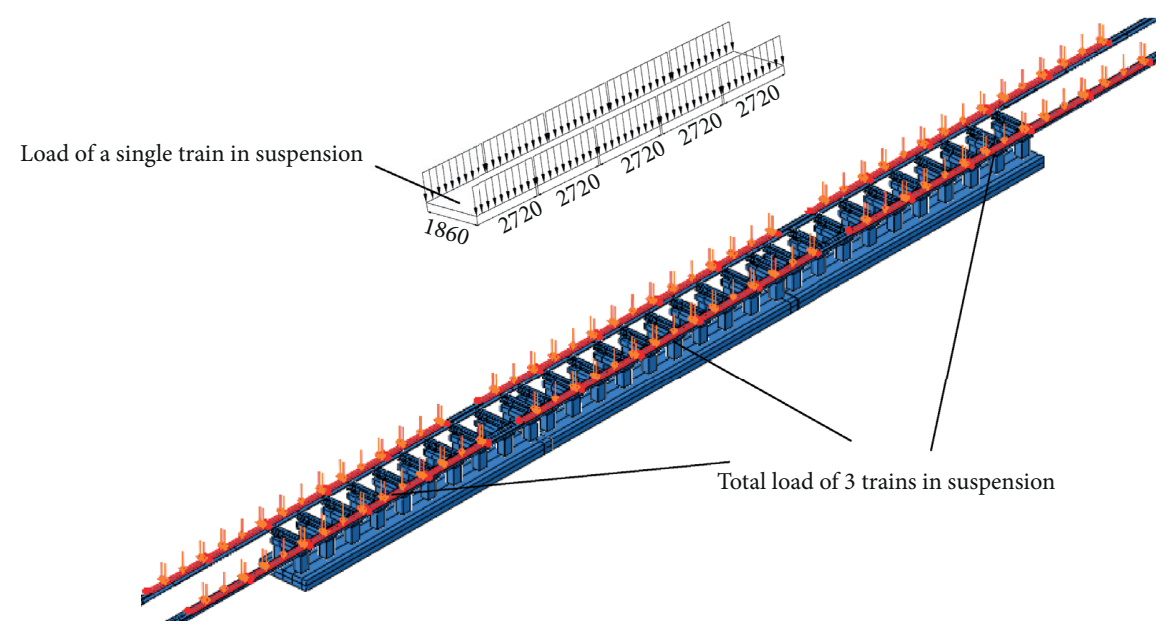

Figure 11: Diagram of the suspended load.

TABLE 2: Summary table of load calculation parameters.

\begin{tabular}{lcc}
\hline Projects & Content & Remark \\
\hline Vertical load of train & $30 \mathrm{kN} / \mathrm{m}$ & Dynamic load of train \\
Track load & $4.52 \mathrm{kN} / \mathrm{m}$ & No rail bearing platform \\
Guiding force & $5.16 \mathrm{kN} / \mathrm{m}$ & Not calculated at the same time as the centrifugal force \\
Traction force & $3.87(2.58) \mathrm{kN} / \mathrm{m}$ & When calculating at the same time with centrifugal force, take the value in brackets \\
Centrifugal force & $5.5 \mathrm{kN} / \mathrm{m}$ & Not calculated at the same time as the guiding force \\
Wind load & $1.92 \mathrm{kN} / \mathrm{m}$ & Basic wind pressure is set at $0.4 \mathrm{kN} / \mathrm{m}^{2}$ \\
\hline
\end{tabular}

TABLE 3: The comparisons of computing results.

Comparing parameters Simulation results Field measurements

Vertical deformation amplitude $(\mathrm{mm})$ Vertical acceleration amplitude $\left(\mathrm{m} / \mathrm{s}^{2}\right)$

$\begin{array}{ll}1.06 & 1.91 \\ 2.15 & 1.35\end{array}$

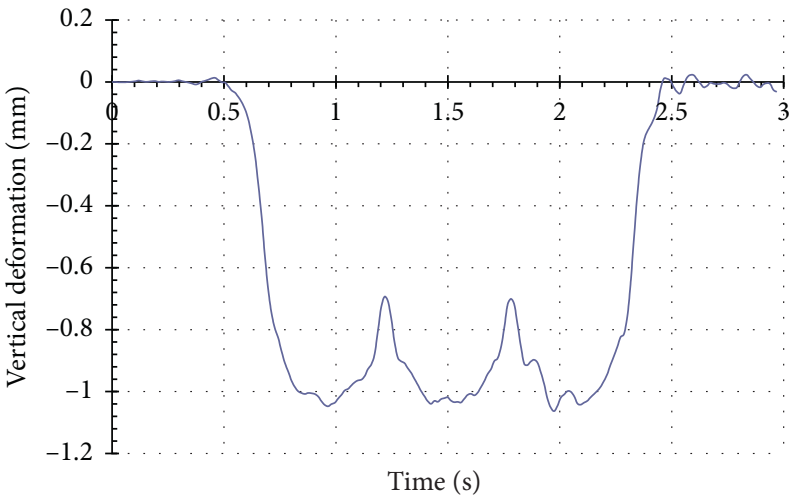

(a)

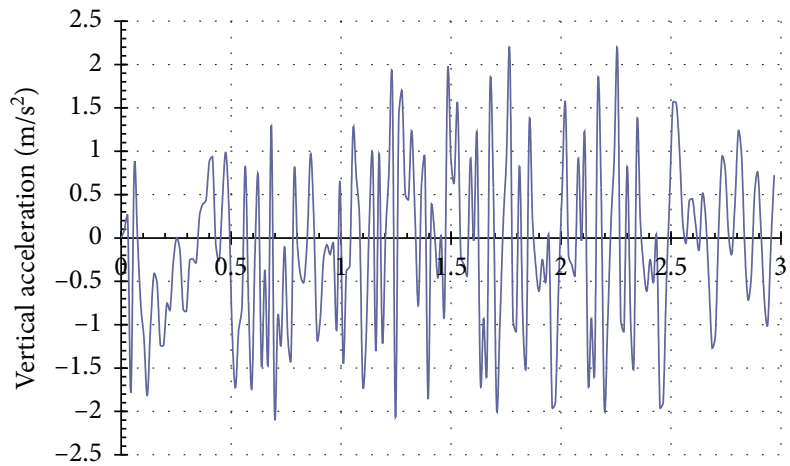

Time (s)

(b)

FIGURE 12: The calculation results: (a) time history response of rail vertical deformation; (b) time history response of $\mathrm{F}$ rail of vertical acceleration. 


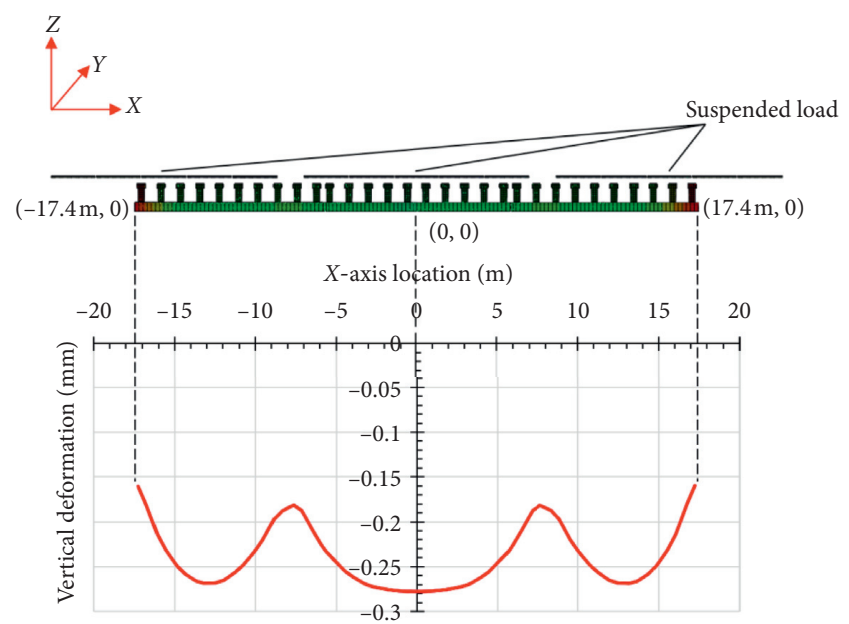

Figure 13: Vertical deformation distribution curve of the top plate under static load $(Y=0)$.

The top plate $(Y=0)$ where the vertical deformation is the largest in the structure was selected, and the vertical deformation responses when the train passes at different speeds were extracted, as shown in Figure 14.

It can be seen from Figure 14 that the vertical deformation time history curve of the top plate has three peaks, which are caused by the three trains passing through the top plate. In the case of different velocities, the deformation amplitude is different. It can be seen that with the increase of velocity, the maximum deformation also tends to increase, but the effect is relatively small. Table 3 shows the statistics of the maximum vertical deformation of the top plate under different speed working conditions. When the speed is $160 \mathrm{~km} / \mathrm{h}$, the maximum vertical displacement is about $0.325 \mathrm{~mm}$.

The statistics of the dynamic coefficient at different driving speeds are shown in Table 3 . The maximum vertical deformation of the top plate under the different speeds of the model load is extracted. The dynamic coefficient is the largest at a speed of $160 \mathrm{~km} / \mathrm{h}$ while it is the smallest at a speed of $100 \mathrm{~km} / \mathrm{h}$. So, as the speed increases, the dynamic coefficient also increases, and the dynamic load effect is strong.

4.1.2. Dynamic Acceleration Response Analysis. Similarly, the top plate with the largest vertical deformation and the corresponding base position $(Y=0)$ was selected, and the acceleration response time history at different driving speeds was extracted, as shown in Figure 15.

The response of the top plate acceleration is more sensitive to the change of speed. It can be seen that with the increase of speed, the amplitude of the acceleration of the top plate increases significantly. When the speed reaches $160 \mathrm{~km} / \mathrm{h}$, the acceleration reaches about $\pm 0.21 \mathrm{~m} / \mathrm{s}^{2}$. The three obvious peaks are the acceleration changes caused by the three trains passing through the selected positions. When the speed gradually decreases, the peak value is inconspicuous. The acceleration amplitude is about $0.16 \mathrm{~m} / \mathrm{s}^{2}$

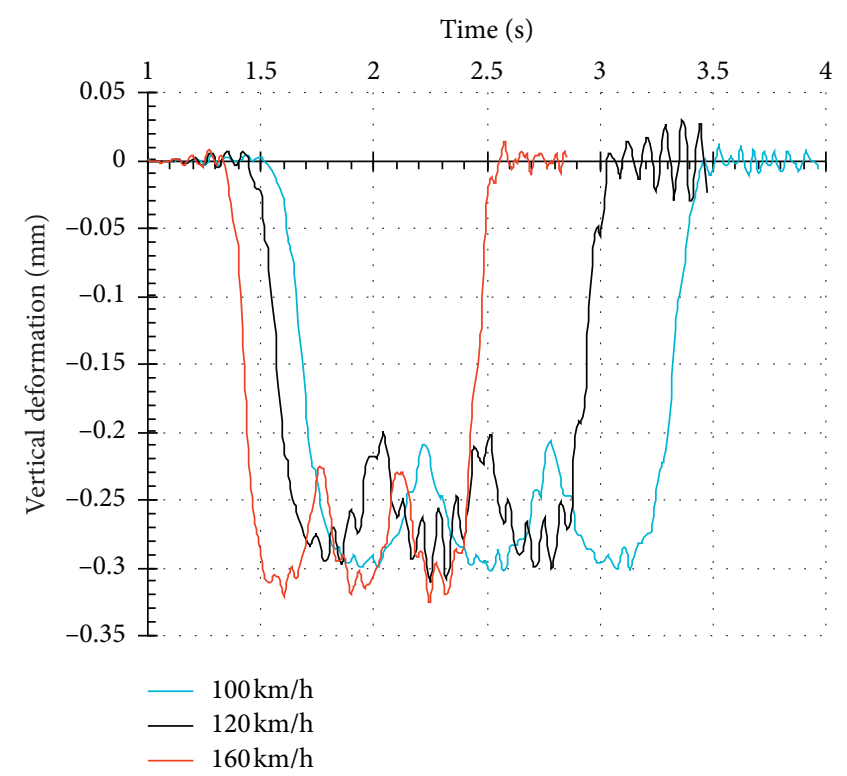

Figure 14: Vertical deformation time course of the top plate at different driving speeds.

at a speed of $160 \mathrm{~km} / \mathrm{h}$ while the acceleration amplitude is about $0.11 \mathrm{~m} / \mathrm{s}^{2}$ at a speed of $100 \mathrm{~km} / \mathrm{h}$.

The acceleration response of the base is weaker than that of the top plate. With the increase of speed, the vertical acceleration gradually increases. But three obvious peaks do not exist, and the amplitude is small compared with that of the top plate. When the speed is $160 \mathrm{~km} / \mathrm{h}$, although the acceleration can reach a value of $0.21 \mathrm{~m} / \mathrm{s}^{2}$, most of the time, the amplitude is $0.18 \mathrm{~m} / \mathrm{s}^{2}$. When the speed is $120 \mathrm{~km} / \mathrm{h}$, the acceleration amplitude is around $0.15 \mathrm{~m} / \mathrm{s}^{2}$. And when the speed is $100 \mathrm{~km} / \mathrm{h}$, the amplitude is about $0.1 \mathrm{~m} / \mathrm{s}^{2}$.

In summary, the increase in speed has a certain effect on the response of the structure, and the effect on the vertical acceleration of the structure is the most significant. The vertical acceleration increases significantly with the increase in speed. Although the speed has a weak influence on the deformation of the structure, there is also a tendency to increase the response as the speed increases. Therefore, the most unfavorable working condition $(160 \mathrm{~km} / \mathrm{h})$ was selected to analyze the force and deformation of the structure.

4.2. Deformation Response of the Rail Beam. In order to determine the force and deformation characteristics of the rail beam structure under the most unfavorable load, horizontal wind load, centrifugal force, and braking force are also applied to the structure at the same time. The responses of track beam structure are simulated under the combined action of the maglev train load, horizontal load, and temperature load (Working condition 4) at a speed of $160 \mathrm{~km} / \mathrm{h}$. The moment when the train acts on the longitudinal middle position of the rail bearing beam structure is selected. Here, the rail bearing beam structure bears the greatest force. In this case, the deformation distribution of the rail bearing beam structure is explored. 


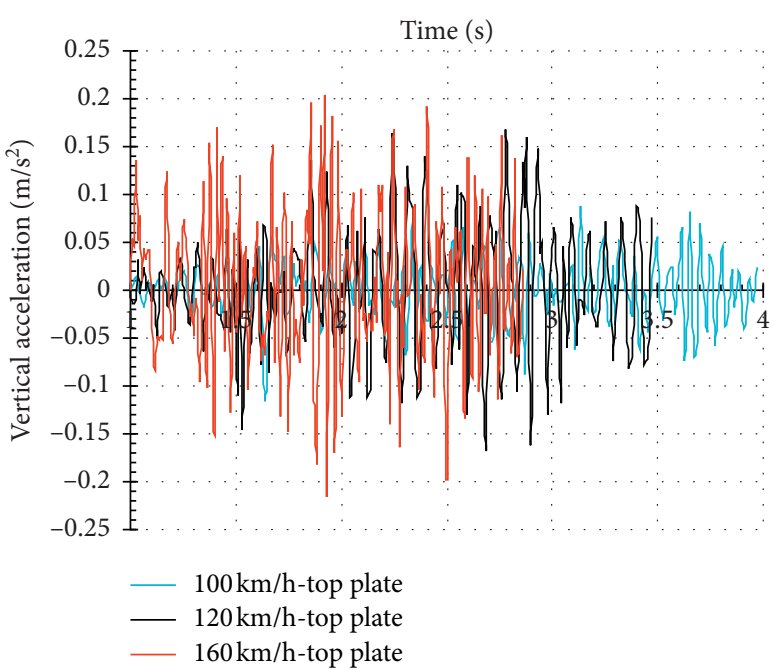

(a)

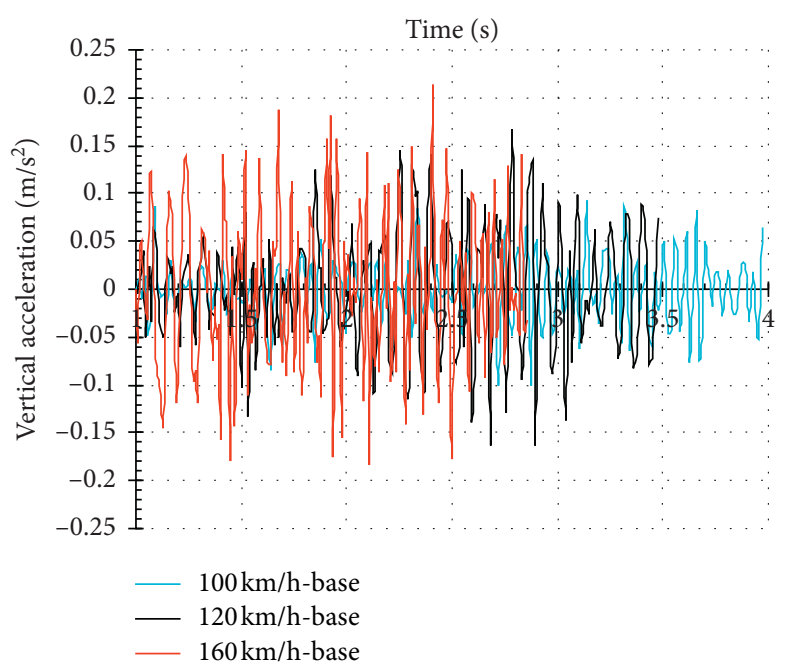

(b)

FiguRE 15: Vertical acceleration time history: (a) vertical acceleration time history of the top plate; (b) vertical acceleration time history of the base.

From the cloud diagram of the cross section of the rail beam shown in Figure 16, it can be seen that the rail beam structure has a large lateral deformation under the action of horizontal load. In addition, the vertical deformation of the structure is uneven, and the opposite direction of the lateral load has a certain degree of warping. The horizontal load direction is the positive direction of the $Y$-axis, and the longitudinal load direction is the negative direction of the $X$ axis. Therefore, the vertical deformation curve of the top plate and the base along the horizontal direction are first extracted, as shown in Figure 17. The rail beam is inclined to a large extent along the positive direction of the $Y$-axis. The top plate and the base have the maximum vertical deformation of $0.606 \mathrm{~mm}$ and $0.939 \mathrm{~mm}$ and the maximum rotation angle of $0.313 \%$ and $0.283 \%$.

As shown in Figure 18(a), the maximum lateral deformations of the top plate and the base are $0.658 \mathrm{~mm}$ and $0.248 \mathrm{~mm}$, respectively. The longitudinal lateral deformations of the top plate and the base are relatively uniform, and the deformations at each position are basically the same. Therefore, the transverse deformations of the column are analyzed by selecting two columns in the longitudinal beam, as shown in Figure 18(b).

Due to the combined action of temperature load and horizontal load, the two columns have a positive lateral deformation. The maximum lateral deformation occurs at the connection between the top of the column and the top plate, with values of $0.469 \mathrm{~mm}$ and $0.708 \mathrm{~mm}$, respectively. There is an expansion in the top and middle of the column, and the maximum rotation angles are $0.254 \%$ and $0.393 \%$, respectively. The column located at $0.43 \mathrm{~m}$ on the $Y$-axis produces a larger rotation angle due to the lateral load.

The upward arching phenomenon of the longitudinally distributed rail beam under the action of temperature load is more obvious than that of the horizontal direction. It can be seen from Figure 19 that the deformation at the expansion

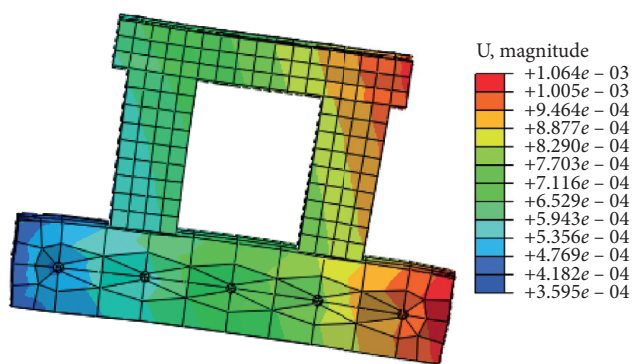

FIgURE 16: Deformation cloud diagram of the rail beam cross section.

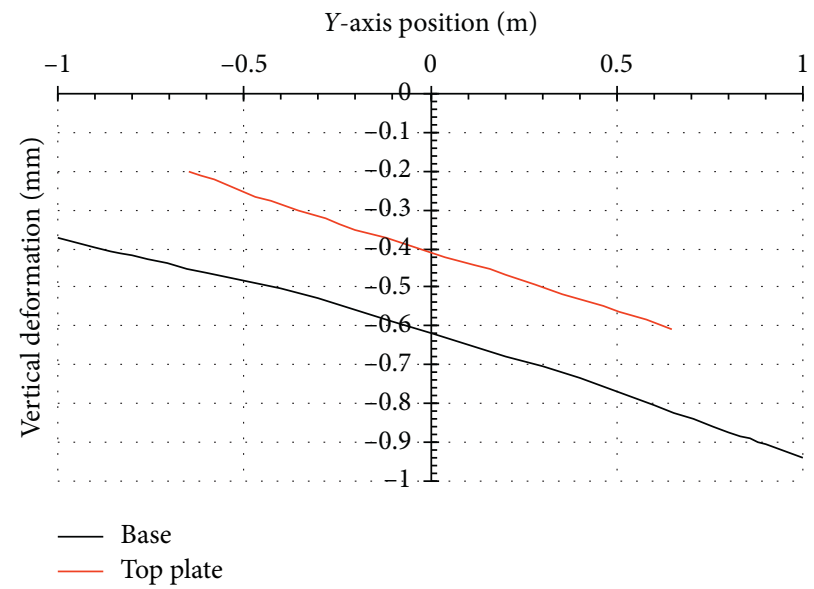

FIgURE 17: The vertical deformation curve of the rail beam along the horizontal direction ( $Y$-axis).

joint is greater than the deformation in the beam. Under the most unfavorable load combination, the top plate and the base have maximum vertical deformations of $0.438 \mathrm{~mm}$ and $0.623 \mathrm{~mm}$, respectively, and the maximum rotation angles of $0.0336 \%$ and $0.0414 \%$, respectively. The effect of the 


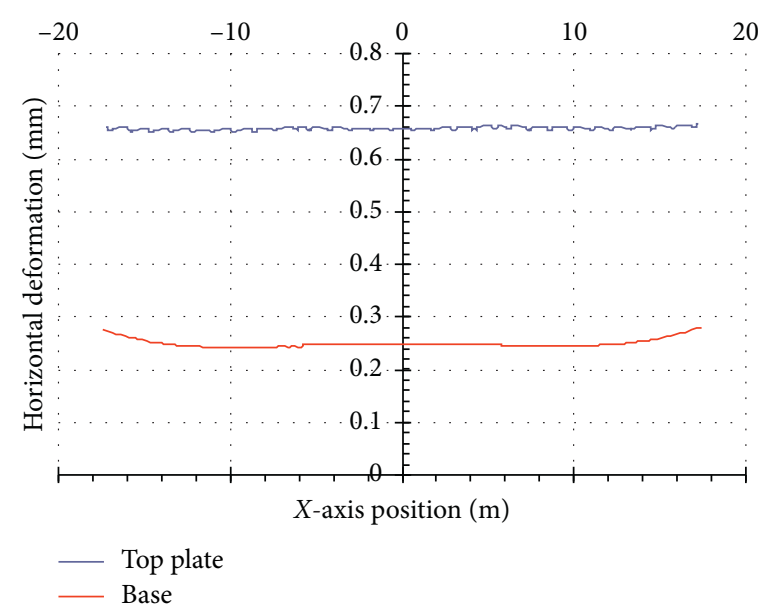

(a)

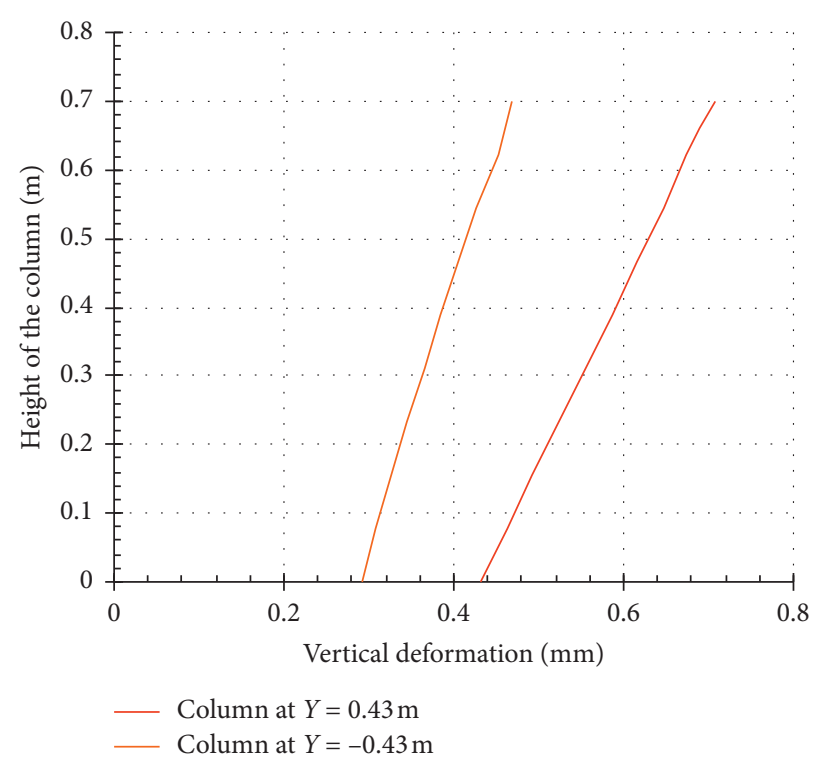

(b)

Figure 18: Deformation curve of rail beam: (a) transverse deformation curve of rail beam long longitudinal direction ( $X$-axis); (b) vertical deformation curve along the height of the column.

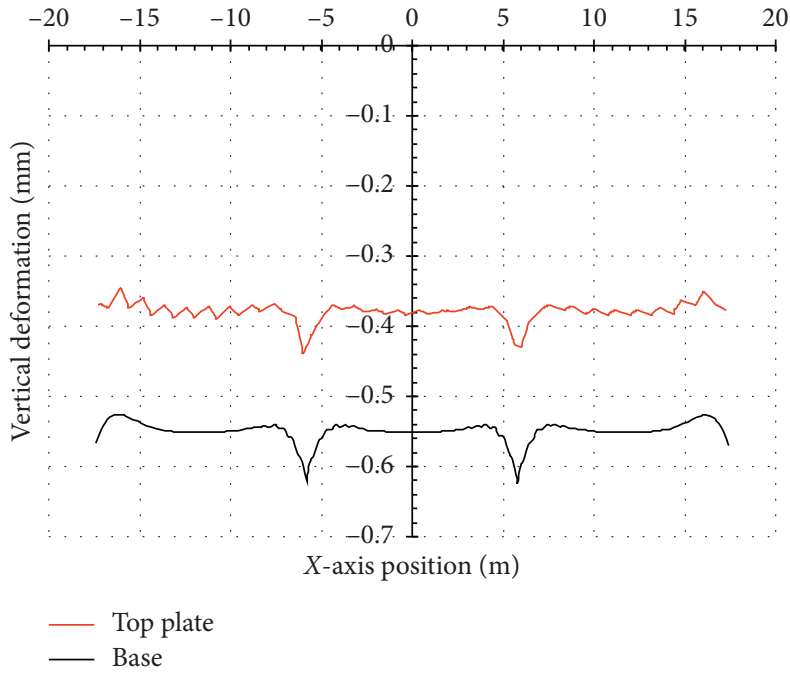

Figure 19: Vertical deformation curve of the rail beam along the longitudinal direction ( $X$-axis).

vertical deformation difference caused by the longitudinal load is not obvious.

The longitudinal deformation of the structure caused by the longitudinal load is different from the beam end. It can be seen that the top plate and the base would swell and deform toward the $X$-axis beam end under the action of temperature load, while the longitudinal load would cause a negative displacement of the structure on the $X$-axis. Thus, the longitudinal deformations of the top plate and the base at the end of the negative coordinate beam with values of $0.205 \mathrm{~mm}$ and $0.359 \mathrm{~mm}$ are greater than the deformation at the end of the positive coordinate beam with values of $0.197 \mathrm{~mm}$ and $0.285 \mathrm{~mm}$. As shown in Figure 20, the temperature load has the greatest influence on the longitudinal deformation.

4.3. Internal Force Response of the Rail Beam. Under the horizontal load, the bending moment of the structure is no longer symmetrical along with the lateral distribution, as shown in Figure 21. The bending moment distributions under the temperature load are compared. And it can be found that the bending moment distribution in the middle $\pm 0.2 \mathrm{~m}$ changes from symmetrical to a form where the bending moment decreases as the coordinate increases. The bending moment of the top plate corresponding to the 


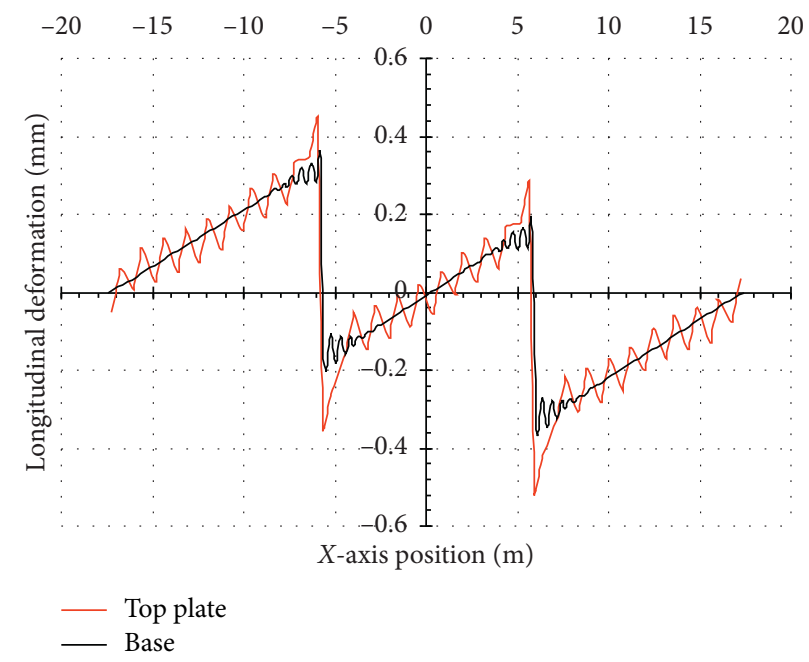

FIgURE 20: The longitudinal deformation curve of the rail beam along the longitudinal direction ( $X$-axis).

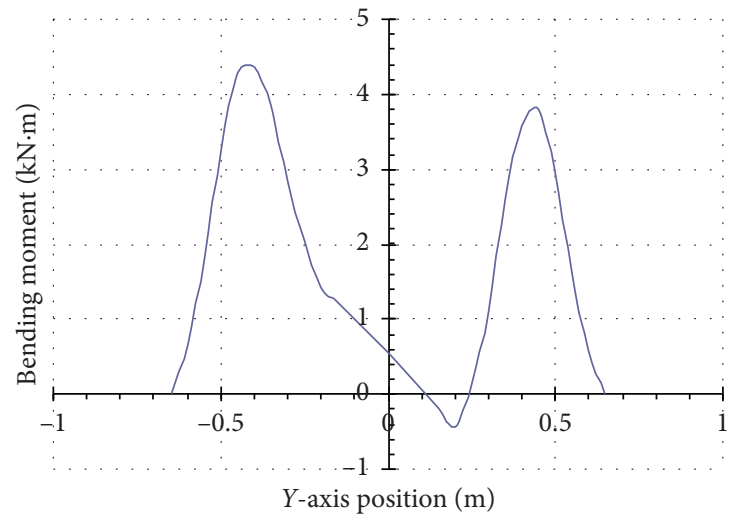

(a)

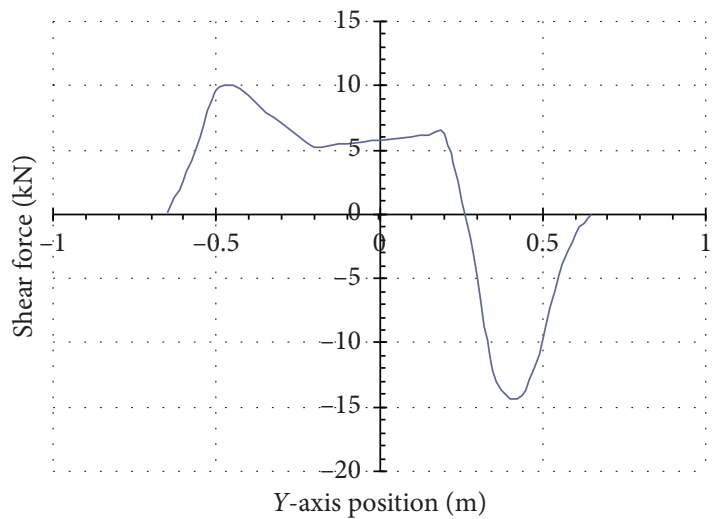

(b)

Figure 21: The top plate along the lateral force distribution map: (a) bending moment; (b) shear force.

column in the positive direction of the transverse load is smaller than that of the negative direction. The maximum bending moment is $4.37 \mathrm{kN} \cdot \mathrm{m}$, and the maximum shear force value is $14.37 \mathrm{kN}$, occurring at the position of $Y=0.4 \mathrm{~m}$ with direction down. It is $43.7 \%$ larger than the positive shear force of $10 \mathrm{kN}$ at $Y=-0.45 \mathrm{~m}$. The lateral load in the positive direction increases the top plate shear force in the positive direction of the $Y$-axis.

The horizontal load also has a great influence on the positive force of the column. As shown in Figure 22, the bending moment and shear force of the column at $0.43 \mathrm{~m}$ are greater than the counterparts of the column at $-0.43 \mathrm{~m}$. The column produces a bending moment at the negative direction at the junction of the bottom and the base with a value of $3.65 \mathrm{kN} \cdot \mathrm{m}$. The maximum bending moment occurs at the height of $0.6 \mathrm{~m}$, with a value of $3.83 \mathrm{kN} \cdot \mathrm{m}$. In addition, the maximum shear force is $15.05 \mathrm{kN}$, which is $334.1 \%$ larger than the shear force of the column at $-0.43 \mathrm{~m}$ with a value of $3.467 \mathrm{kN}$.

The horizontal force distribution of the base is shown in Figure 23. Under the combined load, the bending moment of the base is positive, and the maximum bending moment occurs at the position $Y=0.5 \mathrm{~m}$, with a value of $238.6 \mathrm{kN} \cdot \mathrm{m}$. The maximum shear force occurs at the position of $0.75 \mathrm{~m}$, with a value of $899.5 \mathrm{kN}$.

The longitudinal force distribution law of the base is similar to that when only the temperature load is applied, but the value is different. As shown in Figure 24, the maximum bending moment value is $34.17 \mathrm{kN} \cdot \mathrm{m}$, and the shear force value has increased, with an increase of maximum stress to $35.79 \mathrm{kN}$.

4.4. Self-Vibration Characteristics of the Rail Beam. The selfvibration characteristics of the rail bearing beam structure are analyzed, and the actual working conditions of the structure are simulated. First, the displacement in the horizontal, vertical, and longitudinal directions at the longitudinal ends of the structure is restricted. Then, elastic constraints at the bottom of the base are applied to simulate the effect of the bed. Thus, the self-vibration characteristics of the rail beam structure can be shown in Figure 25 . 


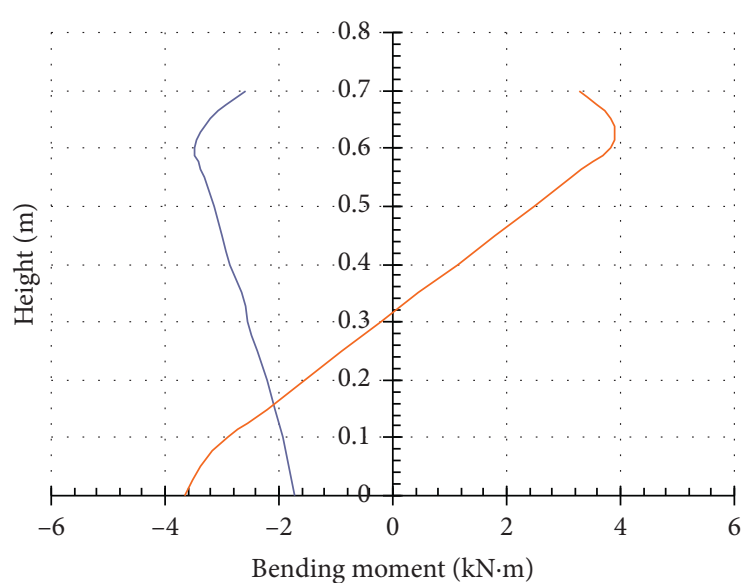

— The left column - The right column

(a)

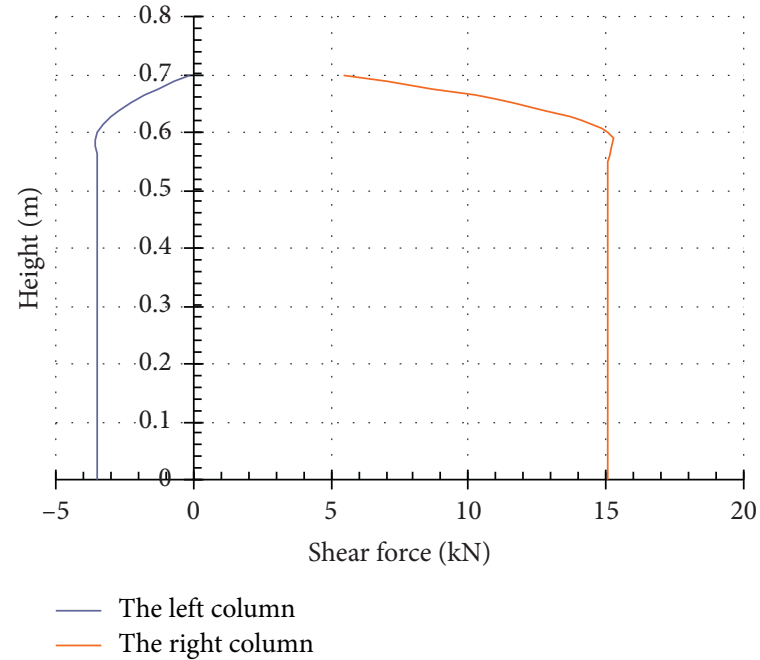

(b)

Figure 22: Distribution of forces along the height of the column: (a) bending moment; (b) shear force.

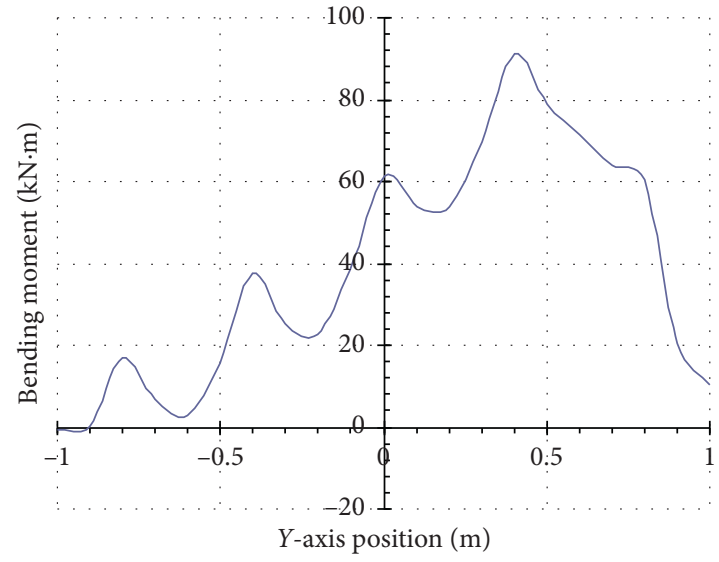

(a)

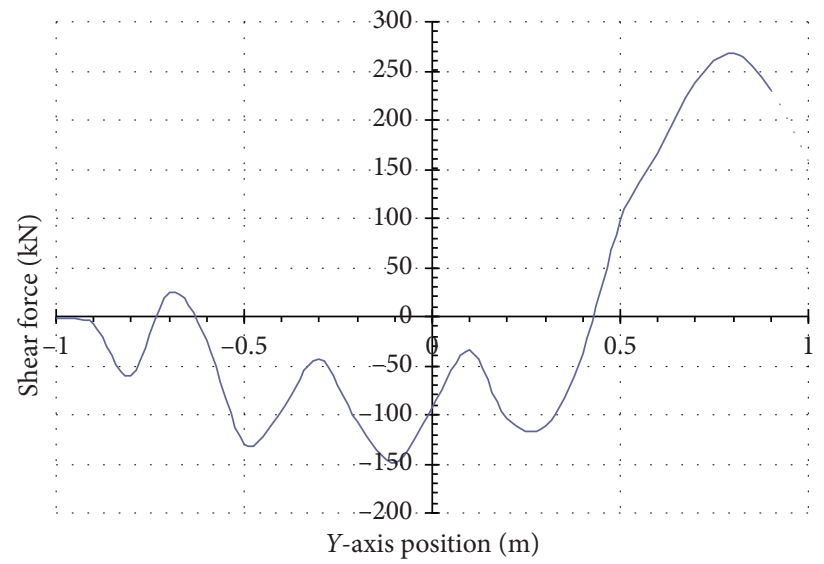

(b)

Figure 23: The lateral force distribution of the base $(X=0)$ : (a) bending moment; (b) shear force.

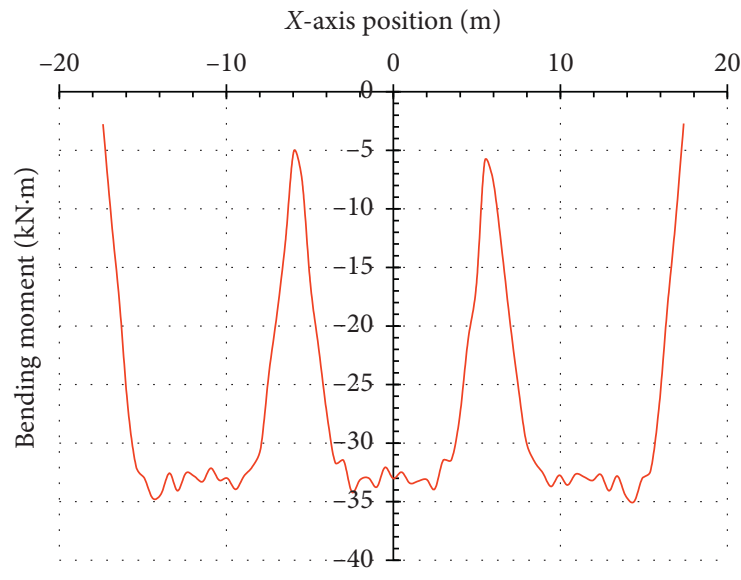

(a)

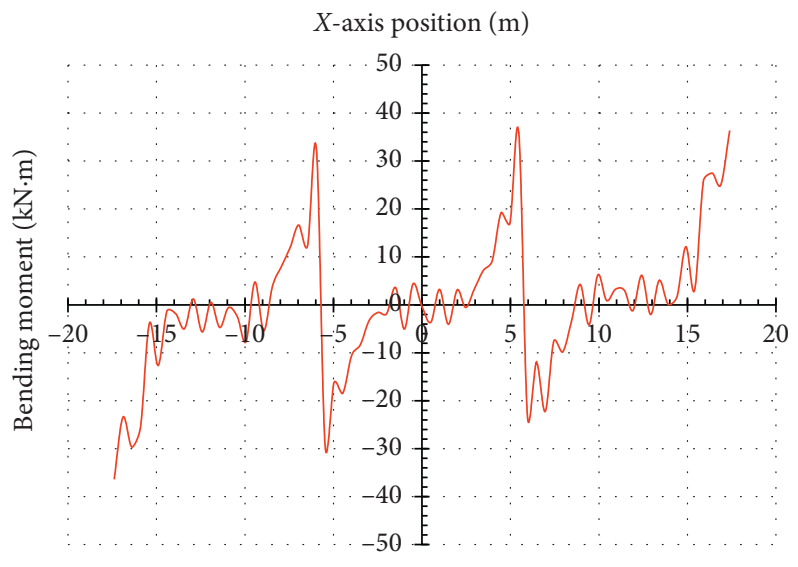

(b)

FIgURE 24: The vertical force distribution of the base $(Y=0)$ : (a) bending moment; (b) shear force. 


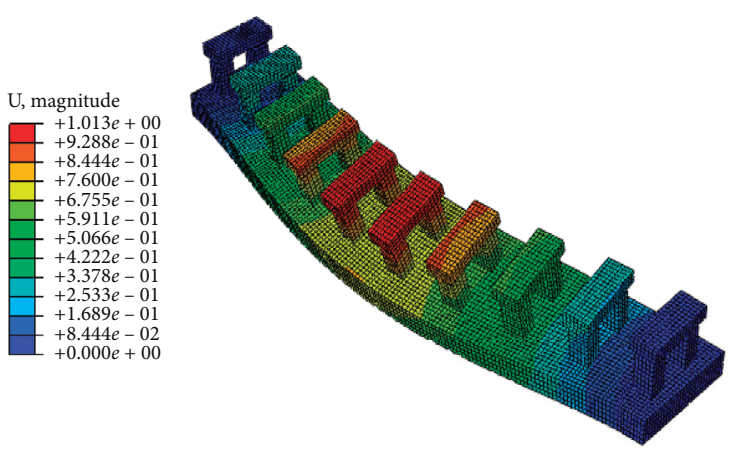

(a)

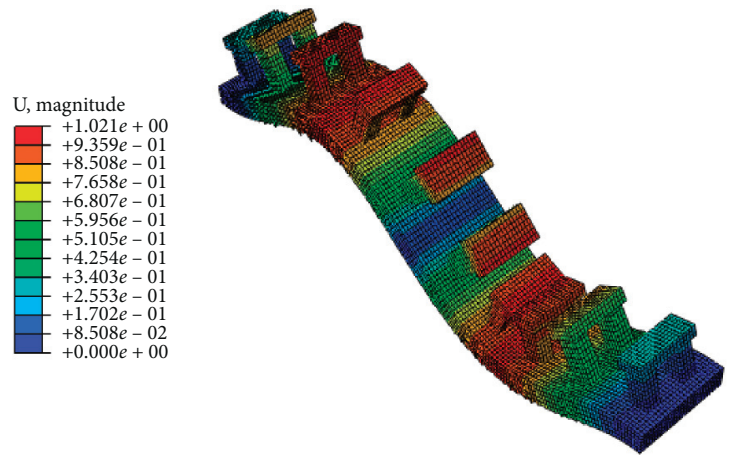

(c)

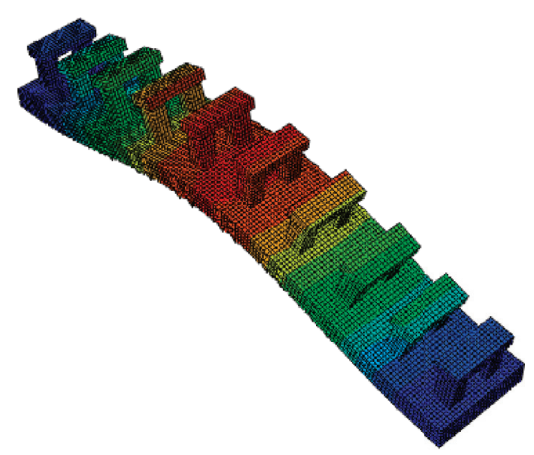

(b)

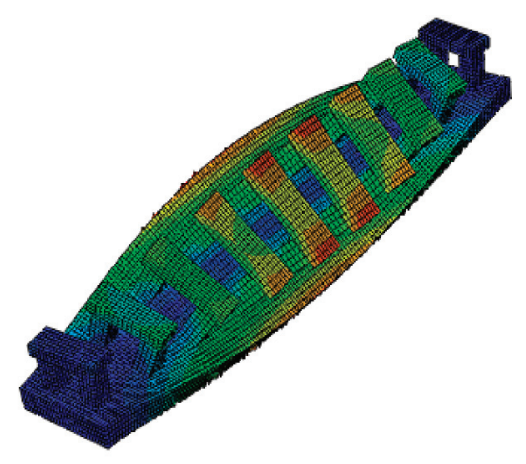

(d)

FIGURE 25: Vibration diagram of the rail beam structure: (a) positive symmetrical torsion; (b) positive symmetric vertical bending; (c) antisymmetric vertical bending; (d) antisymmetric torsion.

TABle 4: Dynamic coefficient of different driving speeds.

\begin{tabular}{lccc}
\hline & $160 \mathrm{~km} / \mathrm{h}$ & $120 \mathrm{~km} / \mathrm{h}$ & $100 \mathrm{~km} / \mathrm{h}$ \\
\hline Maximum deformation under static load $(\mathrm{mm})$ & & 0.2776 & 0.311 \\
Maximum dynamic deformation $(\mathrm{mm})$ & 0.325 & 1.12 & 0.303 \\
Dynamic coefficient & 1.17 & 1.09 \\
\hline
\end{tabular}

TABLE 5: Self-vibration characteristics of the rail beam structure.

\begin{tabular}{|c|c|c|c|}
\hline Modal & Self-vibration frequencies $(\mathrm{Hz})$ & Period (s) & Modal characteristics \\
\hline 1 & 39.97 & 0.025 & Positive symmetrical torsion \\
\hline 2 & 50.02 & 0.02 & Positive symmetric vertical bending \\
\hline 3 & 54.28 & 0.0184 & Antisymmetric vertical bending \\
\hline 4 & 61.18 & 0.016 & Antisymmetric torsion \\
\hline
\end{tabular}

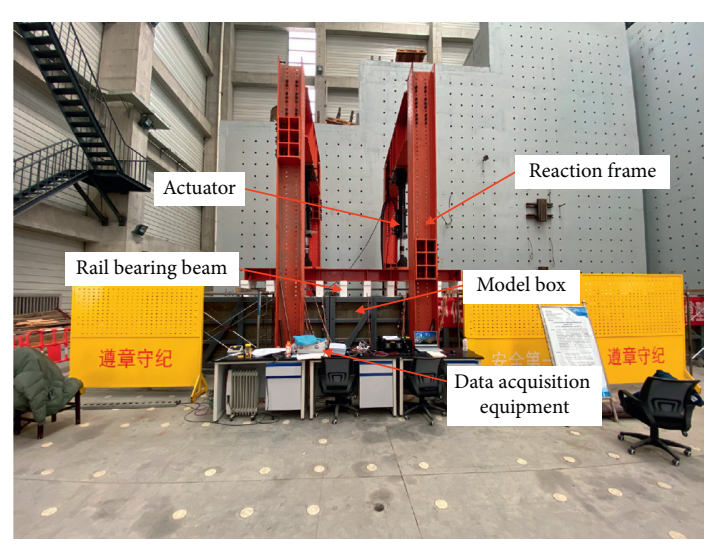

(a)

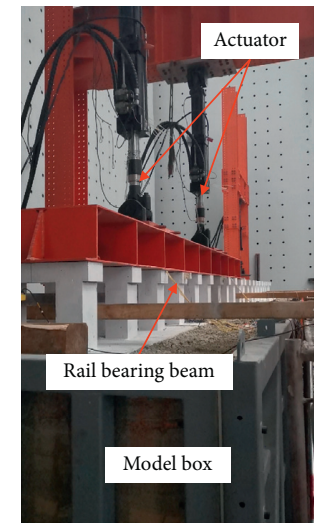

(b)

FIGURE 26: Laboratory model test of the new type of rail bearing beam: (a) the front view of the model; (b) the side view of the model. 
It can be seen from the figure that the vibration mode of the rail beam structure first appears positive symmetrical torsion, followed by positive symmetrical vertical bending, followed by antisymmetric vertical bending and antisymmetric torsion. The self-vibration frequencies are shown in Table 4, which are $39.97 \mathrm{~Hz}, 50.02 \mathrm{~Hz}, 52.28 \mathrm{~Hz}$, and $61.18 \mathrm{~Hz}$, as shown in Table 5.

The analysis of the vibration shape and self-vibration frequency of the structure shows that the self-vibration frequency of the structure is relatively large, which is much higher than the frequency of the maglev load, and the structure is safe. The vibration shape of the rail beam structure is mainly vertical bending and torsion, due to the smaller vertical rigidity of the structure compared with the horizontal.

\section{Conclusion}

In this project, the effect of dowel steel on the rail bearing beam and the response of the rail bearing beam structure under different load conditions and working conditions are analyzed. The main conclusions are as follows:

(1) The rail bearing beam model with dowel steel was used to simulate different driving speeds with moving loads. The results show that the increase in driving speed has the most significant effect on the vertical acceleration of the structure. When the speed increases, its vertical acceleration and vertical deformation and the vertical dynamic stress increase accordingly. And the corresponding dynamic coefficients are $1.17,1.12$, and 1.09 when the speeds are $160 \mathrm{~km} / \mathrm{h}, 120 \mathrm{~km} / \mathrm{h}$, and $100 \mathrm{~km} / \mathrm{h}$, respectively

(2) The internal force and deformation response of each part of the structure under the most unfavorable load conditions (the combination of gravity load, maglev train load, sunshine temperature load, and horizontal load, speed $160 \mathrm{~km} / \mathrm{h}$ ) were simulated. The maximum vertical deformation of the structure is at the end position of the base along the transverse direction, with a value of $0.939 \mathrm{~mm}$. The maximum horizontal deformation is $0.708 \mathrm{~mm}$, which occurs at the top of the column. The maximum longitudinal deformation is $0.359 \mathrm{~mm}$. In addition, the base is the position where the structure generates the largest internal force under the most unfavorable load combination, and the maximum bending moment and shear value are $238.6 \mathrm{kN} \cdot \mathrm{m}$ and $899.5 \mathrm{kN}$, respectively

(3) The constraints of the rail beam structure under actual working conditions were simulated, and the self-vibration frequency and mode shape of the structure were obtained. The self-vibration frequency of the structure is relatively large, and the first-order self-vibration frequency is $39.97 \mathrm{~Hz}$, which is much higher than the load frequency. Besides, the structure is safe

\section{Discussion on Results}

The work in this study is based on the existing achievements in the application of medium-low-speed maglev line rail beams, which is a research on the key technology of a new type of rail beam. The proposed new type of rail beam has a strong practicability and has been applied for related patents. However, other scholars have little research on the new block-type rail beam for medium-low-speed maglev proposed in this study.

Therefore, in order to verify the practicability of the new rail beam structure and the reliability of the finite element model and data, our research group currently proposes a large-scale indoor large-scale model of the medium-lowspeed maglev low-lying structure of the new block-type rail beam. The test has been carried out in the National Engineering Laboratory of Land Transportation Geological Disaster Prevention and Control Technology in Southwest Jiaotong University, as shown in Figure 26. The indoor model test data will be an effective verification of the finite element numerical simulation data. In addition, the on-site driving test will further improve and verify the research results of this study in the future.

\section{Data Availability}

The data used to support the findings of this study are included within the article.

\section{Conflicts of Interest}

The authors declare that they have no conflicts of interest.

\section{Acknowledgments}

This research was funded by China Railway Construction Co., Ltd., under grant no. 2018-A01, and funded by the National Natural Science Foundation of China, under grant no. 51978588.

\section{References}

[1] J. R. Hull, "Magnetic levitation and transportation," Digital Encyclopedia of Applied Physics, pp. 1-19, 2003.

[2] M. Okano, T. Iwamoto, S. Fuchino, and N. Tamada, "Feasibility of a goods transportation system with a superconducting magnetic levitation guide-load characteristics of a magnetic levitation guide using a bulk high-Tc superconductor," Physica C: Superconductivity, vol. 386, pp. 500-505, 2003.

[3] A. Heller, Maglev on the Development Track for Urban Transportation: Science and Technology Review, Lawrence Livermore National Laboratory, Livermore, CA, USA, 2003.

[4] F. Cao, "Comparison and selection of control method for mid-low speed maglev train," Science \& Technology Information, vol. 3, pp. 432-417, 2010.

[5] W. Yang, F. Meng, M. Sun, and K. Liu, "Passivity-based control design for magnetic levitation system," Applied Sciences, vol. 10, no. 7, p. 2392, 2020. 
[6] Y. Ming, Research on Changsha Medium and Low Speed Maglev Gauges, Railway Standard Design, Uttar Pradesh, India, 2017.

[7] Z. Xinxin and C. Branch, "Research on maximum traction control of low and medium speed maglev train of line s1," Journal of the China Railway Society, vol. 39, no. 6, pp. 55-58, 2017.

[8] Z. Yusheng, Z. Chunfa, and Z. Wen, "Natural vibration characteristics of the active turnout girder with different boundary conditions for low-medium speed maglev transit," Railway Standard Design, vol. 64, no. 4, pp. 22-27, 2020.

[9] O. Hibi, "Automatically operated maglev public transport line in Nagoya," Elektrische Bahnen-Charlottenburg Then Berlin Then Munchen, vol. 104, no. 10, p. 480, 2006.

[10] D. Y. Park, B. C. Shin, and H. Han, "Korea's urban maglev program," Proceedings of the IEEE, vol. 97, no. 11, pp. 1886-1891, 2009.

[11] J. Guardo, “U.S. Patent Application No. 11/449,” 2007.

[12] P. Hu, C. Zhang, W. Guo, and Y. Wang, "Dynamic response of a bridge-embankment transition with emphasis on the coupled train-track-subgrade system," Applied Sciences, vol. 10 , no. 17 , p. 5982, 2020.

[13] Q. L. Jiang, J. S. Lian, and D. K. Yue, "Mechanical coupling analysis of single ems module," Journal of the China Railway Society, 2005.

[14] S. Li-Wei, "Research on the lightweight of the beam of maglev train," Journal of Jiamusi University (Natural ENCE Edition), vol. 36, 2018.

[15] Z. Lin, "Tangshan mid and low-speed maglev test line contact rail reformed-the replacement of steel-aluminum contact rail engineering practice," Modern Urban Transit, no. 2, pp. 28-30, 2012.

[16] C. Wen-Feng, X. U. Xi-Jiang, W. U. Cheng-Jin, and Y. Ping, Research on Key Technologies in Track Design of Zhuzhou Medium and Low Speed Maglev Transit Test Line, Railway Standard Design, Uttar Pradesh, India, 2015.

[17] Authour Anonymous, "Code for design of medium and low speed maglev transit (17CJJ/T262)," 2017.

[18] W. L. Jiang and M. M. Gao, "Study of the effect of track beam parameters on vertical coupled dynamic response of maglev vehicle-viaduct," China Railway Science, vol. 3, 2004.

[19] M. Jahangiri and J. A. Zakeri, "Dynamic analysis of trainbridge system under one-way and two-way high-speed train passing," Structural Engineering of Mechanics, vol. 64, no. 1, pp. 33-44, 2017.

[20] J. A. Zakeri, M. Shadfar, and M. M. Feizi, "Sensitivity analysis of bridge-track-train system to parameters of railway," Latin American Journal of Solids and Structures, vol. 11, no. 4, pp. 598-612, 2014.

[21] H. Xia, Y. L. Xu, T. H. Chan, and J. A. Zakeri, "Dynamic responses of railway suspension bridges under moving trains," Scientia Iranica, vol. 14, 2007.

[22] D. Zhao-Feng, Optimization of Key Technical Standards for Ground Structure of Changsha Maglev Express, Railway Standard Design, Uttar Pradesh, India, 2019.

[23] Z. Hongjun and R. Xiongchaohua, "Research on construction procedure of medium-low speed maglev track engineering," Railway Engineering Technology and Economy, 2018.

[24] S. Bhowmick and G.-R. Liu, "Three dimensional cs-fem phase-field modeling technique for brittle fracture in elastic solids," Applied Sciences, vol. 8, no. 12, p. 2488, 2018.

[25] W. Cai, X. Xu, and C. Wu, "Research on the key technology of track design of Zhuzhou medium and low speed maglev trial transportation line," Railway Standard Design, vol. 6, pp. 40-44, 2015.

[26] X. Yi, Research on the Structure Performance of the Track Beam of the Base Track for the Medium and Low Speed Maglev Test Line, Southwest Jiaotong University, Chengdu, China, 2014. 